\title{
Challenging, Hindering Job Demands and Psychological Well-Being: The Mediating \\ Role of Stress-Related Presenteeism
}

* Dr. Nosheen Sarwat (Corresponding Author)

** Dr. Raza Ali

*** Dr. Tariq Iqbal Khan

\begin{abstract}
When individuals are under stress, they cannot fully expend all their energies at work because they are distracted due to stress. This concept is termed stress-related presenteeism. The primary purpose of this research was to analyze the relationship of challenging job demands (i.e., workload) and hindering job demands (i.e., cognitive job demands) with stress-related presenteeism, and the subsequent relationship of stress-related presenteeism with psychological well-being, by using the job-demands resource model and conservation of resource theory. Data $(n=211)$ were collected in two-time waves from bank employees of three major cities of Pakistan. The collected data were analyzed by using bootstrapping mediation analysis. Findings revealed that workload was negatively associated with stress-related presenteeism, whereas cognitive job demands were positively related to stress-related presenteeism. Stress-related presenteeism also mediated the relationships of challenging job demands and hindering job demands with psychological well-being. Implications for managers and recommendations are discussed towards the end of this study...
\end{abstract}

Keywords: Stress-Related Presenteeism, Challenging Job Demands, Hindering Job Demands, Psychological Well-Being

\section{Introduction}

The global economic recession has resulted in many structural changes in modern business organizations. A significant number of organizations have opted for downsizing. The basic premise behind this choice is to do more by using fewer resources. This has resulted in undue pressure on employees in the form of job insecurity, and to attend the work when they are ill or even under stress. Attending work while being ill or in stressful conditions i.e., presenteeism can lead individuals to be present but distracted at work. Such individuals may not expend their full energies to perform workrelated tasks, which can have devastating effects on their overall well-being and performance (Gilbreath \& Karimi, 2012). Researchers in the existing literature has focused more on sicknessrelated presenteeism (Johns, 2010), and have somehow ignored other crucial aspects of presenteeism (Ruhle et al., 2019), for example, stress-related presenteeism.

Individuals working in contemporary organizations face lots of pressures in the form of different demands and expectations from them. These demands can be challenging and/or hindering. However, the individuals must have the necessary personal and organizational resources to fulfill these demands. The job demands resource theory (Bakker \& Demerouti, 2014) explains how job demands can either motivate people or affect their health due to the detrimental effects of such demands. Many researchers have conceptualized job demands as the demands of only one type, which may have negative effects on employees. However, recently some researchers have differentiated job demands and classified them as challenging and hindering job demands. Challenging demands motivate employees; therefore they may positively affect their well-being. In contrast, hindering demands trigger the energy-depleting process; therefore they may hurt the well-being of employees unless they cope with these demands by using the necessary resources (Podsakoff et al., 2007). Do challenging and hindering job demands affect stress-related presenteeism differently; do such job demands affect the psychological well-being of employees differently; and does stress-related

\footnotetext{
* Bahauddin Zakariya University Email: nosheensarwat@bzu.edu.pk

** Bahauddin Zakariya University Email: razaali@bzu.edu.pk

*** The University of Haripur Email: Tariqiqbalkhan@uoh.edu.pk
} 
presenteeism help explain the effects of job demands on the psychological well-being of employees, are some important questions that this study aims to address.

This study uses the job-demands resource model and the conservation of resource theory to investigate the relationships of different job demands with the psychological well-being of employees, by taking into consideration the role of stress-related presenteeism as a mediator in these relationships. Based on previous literature workload is being conceptualized as challenging job demand, whereas cognitive job demands are being considered as hindering job demands in this study Bakker, \& Sans-Vergel, 2013).

\section{Literature Review}

\section{Job Demands and Psychological Well-being}

The characteristics of a work that require the worker to put in a sustained effort and are associated with a certain cost level are called job demands. However, not all types of job demands need to result in some kind of cost and reduce the energy levels of employees. At times, individuals consider their job demands as more of a challenge than a hindrance towards their growth and feel motivated to work. This conceptualization of job demands as being hindering as well as challenge is based on the challenge-hindrance framework by Lepine et al. (2005). They argued that some job types like workload, complexities in a job, and time pressures to complete certain tasks at jobs require effort and energy on the part of the individual but by accomplishing these tasks one feels a sense of goal attainment, learning, and growth. These tasks also increase the competence level of the individual and one feels personal mastery. These job demands are termed as challenging job demands and are associated with positive outcomes at work and contribute towards individual well-being as well.

On the other hand, certain job demands may present potential threats to individuals and they may feel frustrated. Employees feel that by completing such demands they have difficulty in achieving their goals and it also thwarts their personal growth. An example of hindering job demands is insecurity at the job, certain conflicts at the interpersonal level, cognitive and emotional demands that require a lot of energy and effort on the part of the employee. Employees feel that hindering job demands drain their energy and impede growth (Van den Broeck et al., 2010).

The JD-R theory (Bakker \& Demerouti, 2014) posits that when individuals are faced with high job demands for which they have fewer resources to cope, it harms their well-being, on the other hand, job demands which employees perceive as challenging motivate them to put in more efforts and have a positive effect on their well-being. In a daily diary study by Tadic and colleagues, it was found that challenge demands of primary school teachers had a positive effect on their well-being while hindrance job demands hurt their well-being (Tadic, Bakker \& Oerleman, 2015). Hence it is hypothesized that

Hypothesis 1 There is a positive relationship between challenging job demands (workload) and psychological well-being.

Hypothesis 2 There is a negative relationship between hindering job demands (cognitive job demands) and psychological well-being.

\section{Job-Demands and Stress-Related Presenteeism}

The JD-R model has been used by several researchers to study the effects of various job demands on a variety of outcomes. Some researchers also suggest that not all demands need to be equal and cause energy-depleting effects (e.g., Van den Broeck et al., 2010). Podsakoff et al., (2007) classify demands as hindering and challenging. When employees are confident that they can successfully execute a certain demand they appraise it to be challenging. Such demands are challenging and carry a motivational content and the individual expects a certain future gain in fulfilling that demand Crawford et al. (2010) and Van den Broeck et al. (2010). Example of challenging demands includes workload, time pressure and job responsibility (Tims et al., 2013).

On the other hand, when employees feel stress towards the fulfillment of certain demands, they appraise them to be more of a hindrance than a challenge. These are hindering demands and hinder an individual's goal achievement (Dormann \& Zapf, 2004). Example of hindrance demands typically used in research studies includes the function of confrontation, role uncertainty, and emotional demands (Crawford et al., 2010). In a recent study, it has been acknowledged (Bakker \& Sanz-Vergel, 2013) that the type of occupational sector to which individuals belong and the type of job are also important factors in determining the nature of the demand as to be challenging or hindering. For the present research, based on previous studies and keeping in view the banking sector 
workload was identified as a challenging demand and cognitive demands were identified as hindering demands (Tims et al., 2013).

Overall work demands were described as a significant correlate of presenteeism in a recent meta-analysis on the correlates of presenteeism (Miraglia \& Johns, 2016). Similarly, Johns (2010) model on presenteeism also identified job demands as a predictor of presenteeism in organizations. However, since numerous researchers point to the fact that all job demands are not equal, and some job demands can create hindrances in goal achievement but some demands can also create a challenge for the worker by affecting their motivation, it is hypothesized that workload will be negatively related to stress-related presenteeism.

Cognitive demands were considered as hindering job demands for this study. As it has been argued above that the occupational setting in which the job demands are studied has a profound effect on the type of demands being selected cognitive demands were selected based on the competitive nature of the banking industry. Since banking professionals have to work under time pressures and deal with several customers daily and this requires a continued effort while managing their emotions.

Based on the postulates of the COR theory (Hobfoll, 2001), it is hypothesized that when stressful demands will be depleting the resources of the employee the individual will choose to be present at work despite being distracted so that available resources can be used to cope up for the lost work. In a meta-analytical test performed by Crawford, LePine, and Rich (2010) employees who appraised job demands as hindrances their demands related negatively to their ability to work with full devotion and in contrast, employees who appraised demands as challenges were found to be more engaged at work.

Hypothesis 3 There is a negative relationship between challenging job demands (workload) and stress-related presenteeism.

Hypothesis 4 There is a positive relationship between hindering job demands (cognitive job demands) and stress-related presenteeism.

\section{Stress-Related Presenteeism and Psychological Well-Being}

When people communicate with their environments, they are likely to become victims of stress. This likelihood is increased when the interaction becomes threatening and people feel that they do not have enough resources and capabilities to deal with this stress and in such a situation their well-being can be seriously affected (Folkman, 1984; Humpel \& Caputi, 2001). It is well documented in the literature that prolonged exposure to stressful situations like high job demands can expose individuals to various physical and mental health-related problems (Pohling et al., 2016).

To gain the people's advantage, organizations must have a healthy and productive workforce. Along with physical health, psychological health is of equal importance. In explaining the construct of psychological well-being, Ryff (1995) articulated that people should not only be free from distress or cognitive problems to be psychologically well but they should also be able to find a positive meaning in their life and relations and they should have a feeling of continued growth and development. The literature on stress and its negative effect on an individual's well-being is well documented. To date, numerous empirical studies are available which show the devastating effects of stress on an individual's well-being (cf Witte, 1999). However, the present research will examine a situation in which an individual is not only under stress but also can't escape it, since he has to be present as well to fulfill job demands and this may even worsen his health conditions by exacerbating emotional exhaustion (Demerouti et al., 2009).

\section{Hypothesis 5 There is a negative relationship between stress-related presenteeism and psychological well-being}

Mediating Role of Stress-Related Presenteeism between Job Demands and Psychological Wellbeing

Though psychological well-being has been a well-researched construct in the domain of the job demands-resource model, most studies on psychological well-being have been on samples of health care professionals mainly nurses (see for example Albrecht, 2015; Kimber \& Gardner, 2016).

Researchers have studied the effect of job demands on presenteeism and well-being and predicted the mediating relationship (Demerouti et al., 2009), however, what needs to be researched is that are these job demands the same, and do they have the same kind of effects on employee health and well-being. Challenge demands have positive relations with work engagement and burnout (Crawford et al., 2010). On the other hand, employees appraise hindrance demands as being 
hindrances in achieving their personal and professional goals (Dormann \& Zapf, 2004). Researchers have studied some challenging and hindering job demands. Challenging demands which have been included in various studies include workload, job responsibility, and time pressure (Tims et al., 2013) while hindrance demands include emotional demands, role ambiguity, role conflict, etc. (Crawford et al., 2010). Based on their meta-analysis of 64 studies on challenging and hindering job demands Crawford et al., (2010) further expanded the JD-R model and proposed that job demands can be both hindering and challenging. Their findings also proposed that both challenging and hindering job demands may lead to energy depletion and increase employee burnout but challenging job demands can also trigger positive emotions and increase engagement on the other hand hindering job demands will trigger negative emotions and decrease engagement.

The COR (Conservation of resource) theory states that when faced with such energydepleting situations as caused by high hindering job demands, people will try investing their available resources to cope with this resource loss and attend work but in highly stressful conditions leading to high stress-related presenteeism and in turn low well-being resulting from the negative emotion of the hindering job demand (Hobfoll et al., 1990). On the other hand, the challenging job demand can reduce stress-related presenteeism since it is helping the individual achieve work-related goals and the positive emotion produced by the challenging job demand will have a positive effect on well-being by reducing stress-related presenteeism. Using the JD-R model McGregor and colleagues predicted that presenteeism is a significant result of the health impairment process in that it is positively and significantly related to burnout and negatively related to work engagement in the motivational theory of the JD-R model (McGregor et al., 2016), however, in the current study, stress-related presenteeism has been proposed as a psychological mechanism and job demands have also been differentiated as challenging and hindering.

Hypothesis 6 Stress-related presenteeism (SRP) will mediate the relationship between challenging job demands (workload) and psychological well-being

Hypothesis 7 Stress-related presenteeism (SRP) will mediate the relationship between hindering job demands (cognitive job demands) and psychological well-being

Figure 1 presents the conceptual model that is based on the hypotheses stated above.

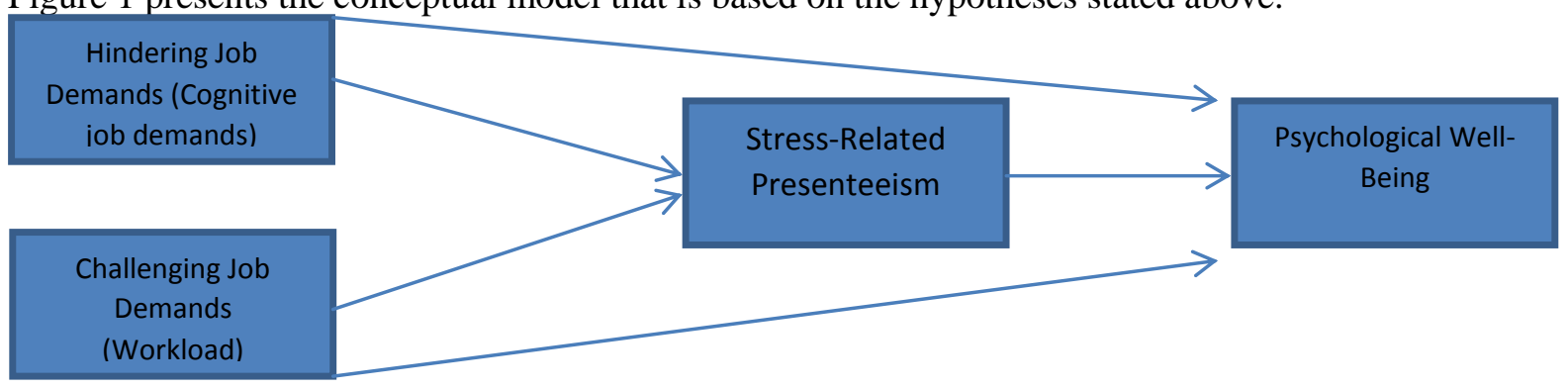

Figure 1: Conceptual Model

\section{Methodology}

Since all the measures were self-reported, a time lag was created with two waves of data collection to avoid common method bias, by keeping in view the techniques described by Podsakoff et al. (2003). Data related to independent variables (i.e., workload and cognitive job demands) were collected at T1. At T2, data related to the mediator variable (i.e., stress-related presenteeism) and dependent variable (i.e., psychological well-being) were collected. Full-time bankers working at various levels in banks (including domestic and multinational banks) operating in Pakistan formed the population of the current study. Keeping in view the purpose of this study, the banking industry of Pakistan appeared to be an appropriate choice for understanding work pressures and individual coping mechanisms to deal with these work pressures. Evidence for stress-related presenteeism in the banking industry in Pakistan has also been identified by other researchers (cf Sarwat \& Shahzad, 2017), and many researchers have tested western theories on service sector professionals (cf Abbas et al., 2014; Sarwat \& Abbas, 2020; Aziz et al., 2019).

\section{Instruments and Measures}

Instruments The instruments used in the present study and their detail is given below. All measures were tapped on a five-point Likert scale.

\begin{tabular}{lllll}
\hline Variable & Instrument & No. & of & Sample items \\
\hline
\end{tabular}




\begin{tabular}{|c|c|c|c|}
\hline & Author(s) & items & \\
\hline Cognitive demands & $\begin{array}{l}\text { Van Veldhoven \& } \\
\text { Meijman (1994) }\end{array}$ & 7 & Does your work demand a lot of concentration? \\
\hline Workload & Karasek (1985) & 11 & Are you behind in your work activities? \\
\hline $\begin{array}{l}\text { Stress-related } \\
\text { presenteeism }\end{array}$ & $\begin{array}{l}\text { Gilbreath and Frew } \\
\text { (2008) }\end{array}$ & 6 & $\begin{array}{l}\text { I spend a significant proportion of my workday } \\
\text { coping with work stress }\end{array}$ \\
\hline $\begin{array}{l}\text { Psychological well- } \\
\text { being }\end{array}$ & Ryff (1995) & 12 & I have been feeling unhappy or depressed \\
\hline
\end{tabular}

\section{Data Collection Procedures}

400 questionnaires were distributed to full-time employees of the four selected commercial banks, i.e. United Bank Limited, Habib Bank Limited, Meezan Bank Limited, and Summit Bank Limited. The research design was time-lagged, and data were collected at two different points of time (i.e., T1 and T2) from the same respondents of these banks. The final sample size comprised 211 responses and the response rate was $52 \%$. The respondents were managers working at various levels in banks with an average age of 32 years and an average work experience of 4-6 years. $70 \%$ of the total respondents were males with a minimum qualification of masters.

\section{Control variables}

The effects of age, experience, and job nature were controlled in this study. Several research studies and meta-analyses have revealed that these variables can have profound effects on psychological wellbeing (see, for example, Pohling et al., 2016).

\section{Results}

Table 1 depicts the correlations of the study variables. The alpha reliabilities have been given in the parenthesis. All reliabilities were according to acceptable standards, and the correlation coefficients between the study variables also supported the hypotheses.

\begin{tabular}{|c|c|c|c|c|c|c|c|c|c|}
\hline No. & Variable & 1 & 2 & 3 & 4 & 5 & 6 & 7 & 8 \\
\hline 1 & Age & - & & & & & & & \\
\hline 2 & Gender & .23 & & & & & & & \\
\hline 3 & Job nature & $.16^{* *}$ & $-.17^{* *}$ & & & & & & \\
\hline 4 & Education & $.19^{* *}$ & .02 & .09 & & & & & \\
\hline 5 & Experience & $.83^{* *}$ & $-.20^{* * *}$ & $.20^{* *}$ & $.22^{* *}$ & & & & \\
\hline 6 & $\begin{array}{l}\text { Cognitive } \\
\text { Demands (T1) }\end{array}$ & .01 & $.19^{* * *}$ & -.08 & .02 & .07 & $(.75)$ & & \\
\hline 7 & Work load (T1) & .05 & .04 & -.04 & .03 & .07 & $.46^{* *}$ & $(.70)$ & \\
\hline 8 & $\begin{array}{l}\text { Stress-related } \\
\text { Presenteeism (T2) }\end{array}$ & $-.11^{*}$ & .02 & $.12^{*}$ & .06 & -.06 & $.15^{* *}$ & $-.11 *$ & $(.81)$ \\
\hline 9 & $\begin{array}{l}\text { Psychological } \\
\text { Well-being (T2) }\end{array}$ & -.07 & .02 & -.02 & .03 & -.07 & $-.12 *$ & $.15^{* *}$ & $-.37 * \quad(.71)$ \\
\hline
\end{tabular}

Note. $\mathrm{N}=211$; Alpha reliabilities are presented in parenthesis; $\mathrm{T}=$ "Time"

$* \mathrm{P}<.05, * * \mathrm{p}<.01$

Bootstrap for indirect effects of workload on psychological well-being through stress-related presenteeism (SRP)

The results in Table 2 depict that challenging job demands (workload) harmed SRP $(B=-.14, p<.05)$ (Hypothesis 3). SRP was negatively related to psychological well-being $(B=-.36, p<.01)$ as shown in table 2 (Hypothesis 5). The direct impact of workload on psychological well-being was insignificant $(\mathrm{B}=.01, \mathrm{~ns})$ (Hypothesis 1$)$. The bootstrap indirect effect of workload on psychological well-being $(B=0.05)$ was significant through SRP as the bootstrapped confidence interval did not include a zero (CI: 0.01, 0.09). The results supported hypothesis 6 .

Bootstrap for indirect effects of cognitive job demands on psychological well-being through stress-related presenteeism (SRP)

Cognitive job demands were positively related to SRP $(\mathrm{B}=.13, \mathrm{p}<.05)$ as shown in Table 3 (Hypothesis 4). SRP was negatively related to psychological well-being $(B=-.36, p<.01)$ (Hypothesis 5). The direct impact of cognitive demand on psychological well-being was insignificant (B = -.02, ns) (Hypothesis 2). The bootstrap indirect effect of cognitive job demands on psychological 
well-being $(\mathrm{B}=-0.05)$ was significant through SRP as the bootstrapped confidence interval did not include a zero (CI: $-0.02,-0.09)$. The results supported hypothesis 7 .

Table 2: Main effects, and mediation of stress-related presenteeism (SRP) in the relationship between workload and psychological well-being

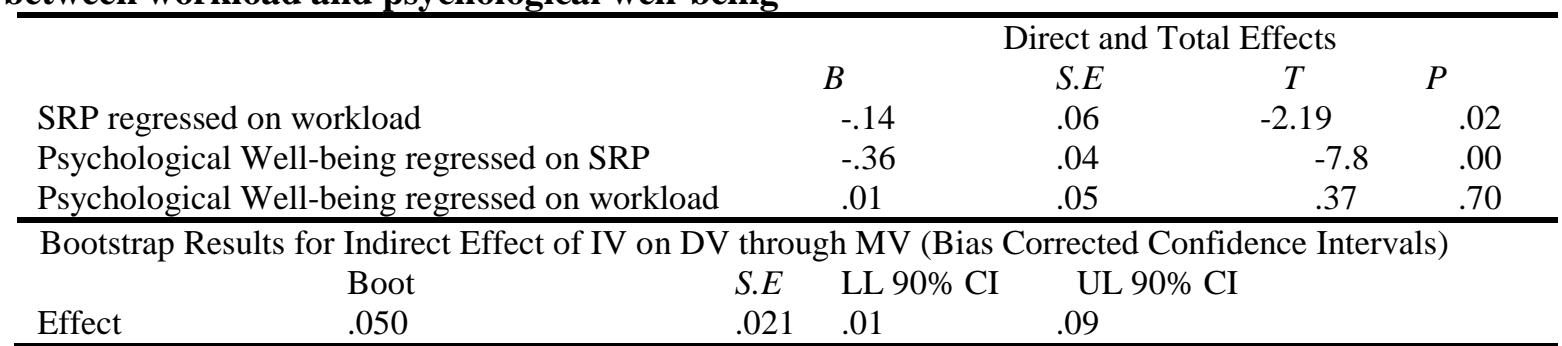

Note. $N=211$. Unstandardized regression coefficients are reported. Bootstrap sample size $=5,000$. $\mathrm{LL}=$ lower limit; $\mathrm{CI}=$ confidence interval; $\mathrm{UL}=$ upper limit. Age, gender and experience were controlled in all analysis.

Table 3: Main effects, and mediation of stress-related presenteeism (SRP) in the relationship between cognitive job demands and psychological well-being

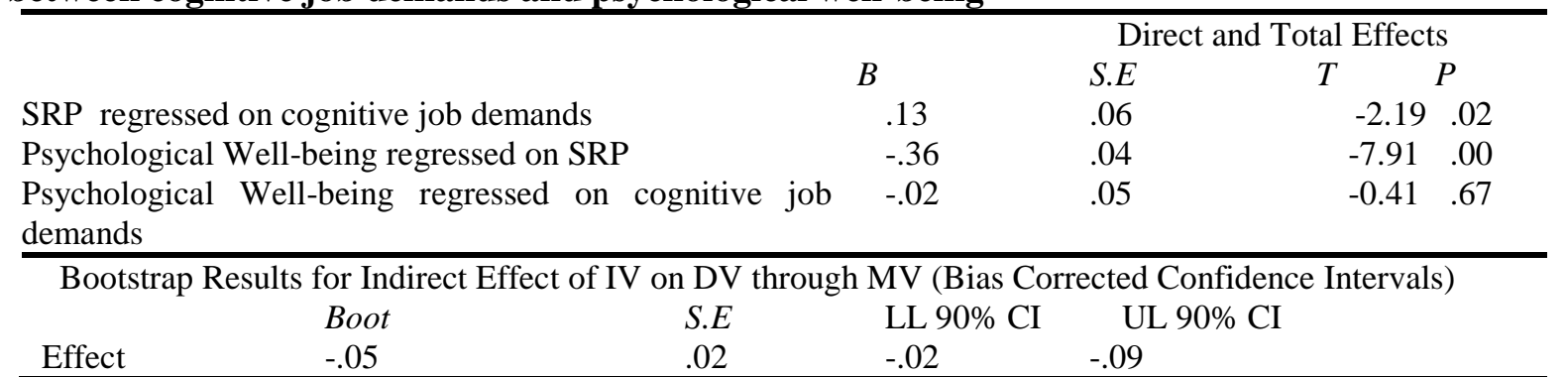

Note. $N=211$. Unstandardized regression coefficients are reported. Bootstrap sample size $=5,000$. $\mathrm{LL}=$ lower limit; $\mathrm{CI}=$ confidence interval; $\mathrm{UL}=$ upper limit. Age, gender and experience were controlled in all analysis.

\section{Discussion}

To date research on presenteeism has been lacking the integration of a proper theory (Johns, 2010). This presents some challenges for the researchers studying this phenomenon. Most research on presenteeism has been conducted from a health-related perspective (Cooper, 2016). The term sickness-related presenteeism which is defined as coming to work while ill has been used by the majority of researchers (Johns, 2012). Though are other types of presenteeism as well like non-workrelated presenteeism, in this study stress-related presenteeism was defined as when employees are physically present at their workplace, but their emotional energy is distracted from their job, preventing them from paying full attention to their jobs (Gilbreath \& Karimi, 2012)?"

The primary objective of this study was to examine the relationship of challenging and hindering job demands with stress-related presenteeism and its subsequent relation with psychological well-being using the job-demands resource model and conservation of resource theory. The workload was conceptualized as a challenging job demand and cognitive job demands were considered hindering job demands.

The literature on the relationship between work demands and psychological well-being is well described. The present study examined the relationship between job demands and psychological wellbeing. Job demands were classified as challenging and hindering since it is evident from previous research studied that all job demands are not equal and they can have differentiating effects on various outcomes.

The workload was conceptualized as a challenging job demands having positive effects on an individual's well-being. When individuals take their workload as a challenge, they feel more engaged in their work since they believe that by completing this workload they will be able to achieve their work-related goals which will boost their personal growth having a positive effect on their well-being. The negative relationship between hindering job demands and psychological well-being was also accepted for cognitive job demands. The JD-R theory and subsequent studies have argued for the 
negative effect of high cognitive demands and low resources on individual well-being (Bakker, 2011; Tadic et al., 2015). Cognitive demands are hindering the performance of employees and this can lead to certain stressful emotions subsequently affecting their well-being.

Job-demands can play a crucial role both in the motivational and health impairment processes, job demands were classified as challenging (workload) and hindering (cognitive) in light of relevant literature (Tims et al., 2013; Albrecht, 2015) to study the differential effects of job demands on stress-related presenteeism. Support was found for the positive relation of cognitive demands and negative relation of the workload with stress-related presenteeism as hypothesized. When demand is appraised as challenging, it promotes positive expectations of individuals and thereby will reduce stress-related presenteeism. Challenging demands are known to trigger the positive emotions of the individuals since they are seen as a means of achieving work-related outcomes, the individual expends more efforts and is ready to invest more energy to fulfill that demand, because of the overall positive outcome (Lazarus \& Folkman, 1984; Crawford, Lepine \& Rich, 2010).

The results also supported a positive relationship between cognitive job demands and stressrelated presenteeism. Cognitive demands are a type of hindering demands since individuals have to expend more effort cognitively to fulfill such demands and this can increase their stress levels. Moreover, hindering job demands are negatively appraised by individuals and are considering threatening and creating obstacles for their personal growth (Lazarus \& Folkman, 1984). When individuals face uncertainty at work they become less cognitively engaged since they do not know what they have to do at work and therefore will not be able to devote all their energies at work (Harter, Schmidt \& Hayes, 2002) and hence will become victims of stress-related presenteeism.

As hypothesized, stress-related presenteeism was negatively related to psychological wellbeing. These results were in line with some research studies for example Karimi et al., (2015) found a negative relation between nurses well-being and SRP; Pohling et al., (2016) study supported the same results on a German sample of public sector employees and in a systematic review conducted by Skagen and Collins (2016) presenteeism in terms of productivity loss harmed the physical and mental health of individuals.

The present study also tested the mediating role of stress-related presenteeism between challenging job-demands, hindering job-demands, and psychological well-being. The findings of this research offered evidence for mediation of stress-related presenteeism between cognitive demands, workload psychological well-being. Psychologically disturbing demands like cognitive demands were positively related to psychological stress which led to presenteeism. When individuals feel the pressure of cognitive demands their energies are depleted and this can result in distraction from the current task leading them to delay it and can also negatively affect their well-being. In a recent metaanalysis conducted by Miraglia and Johns (2016) on the correlates of presenteeism, stressing job demands were found to be positively related to job stress and presenteeism and its negative effects on the overall health of an individual. Further, there is a whole stream of research findings that provide evidence for the positive relationship between job demands and stress and the negative relation of stress with an individual's health (Crawford et al., 2010; Schaufeli \& Taris, 2014).

\section{Practical Implications and Recommendations}

The current study presents several implications for practice. Specifically, managers should recognize the fact that all types of job demands that employees face in organizations do not necessarily create stress for them. Some jobs can be challenging and some can be hindering. Jobs should be designed in such a way that individuals take them as challenges, and work with full engagement without being distracted. However, if job demands are hindering, managers need to ensure that employees are provided sufficient resources to deal with those demands. By following such recommendations, managers may reduce the stress-related presenteeism and increase the psychological well-being of their employees, which can help make employees valuable resources for the organization.

This study included only the bankers in the sample. Future researchers may include employees from other dynamic sectors and industries to test the same conceptual model. Similarly, the boundary conditions of the relationships examined in this study may be of interest to future researchers.

\section{References}

Abbas, M., Raja, U., Darr, W., \& Bouckenooghe, D. (2014). Combined effects of perceived politics \& psychological capital on job satisfaction, turnover intentions, \& performance. Journal of Management, 40(7), 1813-1830. 
Albrecht, S. L. (2015). Challenge Demands, Hindrance Demands, \& Psychological Need Satisfaction. Journal of Personnel Psychology, 14(2), 70-79.

Aziz, N., Naseer, S., Ali, R., \& Kanwal, M. (2019). The impact of emotional labor strategies on employee behaviors: A conservation of resources perspective. Pakistan Journal of Social Sciences (PJSS), 39(3), 1021-1035.

Bakker, A. B. (2011). An evidence-based model of work engagement. Current Directions in Psychological Science, 20(4), 265-269.

Bakker, A. B., \& Demerouti, E. (2014). Job demands-resources theory. Wellbeing: A complete reference guide, 1-28.

Bakker, A.B., \& Sans-Vergel, A.S. (2013). Weekly work engagement \& flourishing: the role of hindrance \& challenging job demands. Journal of Vocational Behavior, 83 (2013), 397-409.

Baron, R. M., \& Kenny, D. A. (1986). The moderator-mediator variable distinction in social psychological research: Conceptual, strategic, \& statistical considerations. Journal of Personality \& social psychology, 51(6), 1173-1182.

Cooper, C., \& Lu, L. (2016). Presenteeism is a global phenomenon: Unraveling the psychosocial mechanisms from the perspective of social cognitive theory. Cross-Cultural \& Strategic Management, 23(2), 216-231.

Crawford, E. R., LePine, J. A., \& Rich, B. L. (2010). Linking job demands \& resources to employee engagement \& burnout: a theoretical extension \& meta-analytic test. Journal of Applied Psychology, 95(5), 834-848.

Demerouti, E., Le Blanc, P. M., Bakker, A. B., Schaufeli, W. B., \& Hox, J. (2009). Present but sick: a three-wave study on job demands, presenteeism \& burnout. Career Development International, 14(1), 50-68.

Dormann, C., \& Zapf, D. (2004). Customer-related social stressors \& burnout. Journal of occupational health psychology, 9(1), 61-82.

Folkman, S. (1984). Personal control, stress \& coping processes: A theoretical analysis. Journal of Personality \& social psychology, 46(4), 839-852.

Gilbreath, B., \& Karimi, L. (2012). Supervisor behavior \& employee presenteeism. International Journal of Leadership Studies, 7(1), 114-131.

Harter, J. K., Schmidt, F. L., \& Hayes, T. L. (2002). Business-unit-level relationship between employee satisfaction, employee engagement, \& business outcomes: A meta-analysis. Journal of Applied Psychology, 87, 268-279

Hobfoll, S. E., \& Shirom, A. (2001). Conservation of resources theory: Applications to stress \& management in the workplace.

Hobfoll, S. E., Freedy, J., Lane, C., \& Geller, P. (1990). Conservation of social resources: Social support resource theory. Journal of Social \& Personal Relationships, 7(4), 465-478.

Humpel, N., \& Caputi, P. (2001). Exploring the relationship between work stresses, years of experience, \& emotional competency using a sample of Australian mental health nurses. Journal of Psychiatric \& Mental Health Nursing, 8(5), 399-403.

Johns, G. (2010). Presenteeism in the workplace: A review \& research agenda. Journal of Organizational Behavior, 31(4), 519-542.

Johns, G. (2012). Presenteeism: A short history \& a cautionary tale. Contemporary occupational health psychology: Global perspectives on research \& practice, 2, 204-220.

Karasek, R.A. (1985). Job content instrument: Questionnaire \& users' guide (Rev 1.1). Los Angeles, CA: University of Southern California.

Karimi, L., Cheng, C., Bartram, T., Leggat, S. G., \& Sarkeshik, S. (2015). The effects of emotional intelligence \& stress-related presenteeism on nurses' well-being. Asia Pacific Journal of Human Resources, 53(3), 296-310.

Kimber, S., \& Gardner, D. H. (2016). Relationships between workplace well-being, job demands, \& resources in a sample of veterinary nurses in New Zealand. New Zealand veterinary journal, 64(4), 224-229.

LePine, J. A., Podsakoff, N. P., \& LePine, M. A. (2005). A meta-analytic test of the challenge stressor-hindrance stressor framework: An explanation for inconsistent relationships among stressors \& performance. Academy of Management Journal, 48(5), 764-775. 
McGregor, A., Magee, C. A., Caputi, P., \& Iverson, D. (2016). A job demands-resources approach to presenteeism. Career Development International, 21(4), 402-418.

Miraglia, M., \& Johns, G. (2016). Going to work ill: A meta-analysis of the correlates of presenteeism \& a dual-path model. Journal of Occupational Health Psychology, 21(3), 261-283.

Newman, A., Ucbasaran, D., Zhu, F., \& Hirst, G. (2014). Psychological capital: A review \& synthesis. Journal of Organizational Behavior, 35(S1), S120-S138.

Podsakoff, N. P., LePine, J. A., \& LePine, M. A. (2007). Differential challenge stressor-hindrance stressor relationships with job attitudes, turnover intentions, turnover, \& withdrawal behavior: a meta-analysis. Journal of applied psychology, 92(2), 438-454.

Podsakoff, P.M., Mackenzie, S.b., \& Podsakoff, N.P. (2003). Common method bias in behavioral research: A critical review of the literature \& recommended remedies. Journal of Applied Psychology, 88, 879-903.

Pohling, R., Buruck, G., Jungbauer, K. L., \& Leiter, M. P. (2016). Work-related factors of presenteeism: The mediating role of mental \& physical health. Journal of occupational health psychology, 21(2), 220-234.

Ruhle, S. A., Breitsohl, H., Aboagye, E., Baba, V., Biron, C., Correia Leal, C., \& Yang, T. (2020). "To work, or not to work, that is the question"-Recent trends \& avenues for research on presenteeism. European Journal of Work \& Organizational Psychology, 29(3), 344-363.

Ryff, C. D. (1995). Psychological well-being in adult life. Current directions in psychological science, $99-104$.

Sarwat, N., \& Abbas, M. (2020). Individual knowledge creation ability: dispositional antecedents \& relationship to innovative performance. European Journal of Innovation Management.

Sarwat, N., \& Shahzad, K. (2017). An Investigation into the Role of Mindfulness on the Relationship between Hindering Job Demands \& Stress-Related Presenteeism. Pakistan Journal of Social Sciences (PJSS), 37(2), 608-619.

Schaufeli, W. B., \& Taris, T. W. (2014). A critical review of the job demands-resources model: Implications for improving work \& health. In G. F. Bauer, \& O. Hammig (Eds.), Bridging Occupational, Organizational \& Public Health: A Transdisciplinary Approach. (pp. 43-68). Dordrecht, Netherlands: Springer.

Tadić, M., Bakker, A. B., \& Oerlemans, W. G. (2015). Challenge versus hindrance job demands \& well-being: A diary study on the moderating role of job resources. Journal of Occupational \& Organizational Psychology, 88(4), 702-725.

Tims, M., Bakker, A. B., \& Derks, D. (2013). The impact of job crafting on job demands, job resources, \& well-being. Journal of Occupational Health Psychology, 18(2), 230-240.

Van den Broeck, A., De Cuyper, N., De Witte, H., \& Vansteenkiste, M. (2010). Not all job demands are equal: Differentiating job hindrances \& job challenges in the job demands-resources model. European journal of work \& organizational psychology, 19(6), 735-759.

Van den Heuvel, M., Demerouti, E., Bakker, A. B., \& Schaufeli, W. B. (2010). Personal resources \& work engagement in the face of change. Contemporary occupational health psychology: Global perspectives on research \& practice, 1, 124-150.

Van Veldhoven, M., \& Meijman, T.F. (1994). Questionnaire on the experience \& evaluation of work (QEEW) Preliminary English version. Amsterdam National Research for Working Conditions, Brussels.

Witte, H. D. (1999). Job insecurity \& psychological well-being: Review of the literature \& exploration of some unresolved issues. European Journal of Work \& Organizational Psychology, 8(2), 155-177. 